\title{
Moving forward in public health nutrition - the I World Congress of Public Health Nutrition
}

Lluís Serra-Majem

Advances have been made in public health nutrition, but there is still a long way to go. Alliances and synergies are needed on a global scale and among various stakeholders: scientists, (non-) governmental organizations, healthcare professionals, food industry, media, consumers, and regulators. Partnerships are critical to innovatively combine competencies and resources to address persistent global health problems. The I World Congress of Public Health Nutrition, held in Barcelona from 28 to 30 September 2006, aimed to foster a sound scientific evidence base as well as to provide a forum for networking and alliance building. Participants from 79 countries met to discuss issues and to set conclusions and guidelines for the future. The World Public Health Nutrition Association was founded within this platform to continue these important tasks.

(c) 2009 International Life Sciences Institute

The I World Congress of Public Health Nutrition (I WCPHN) took place in Barcelona, under the auspices of the Spanish Society of Community Nutrition (SENC) and the International Union of Nutritional Sciences (IUNS). A total of 1607 registered participants from 79 countries spent over 30 hours deliberating on the different themes and topics in the areas of nutrition and public health. For the first time, problems related to both under- and overnutrition were analyzed in the same meeting, and the transition between both conditions was examined in particular detail. A renowned International Scientific Committee chaired by Ricardo Uauy and Javier Aranceta created the programme and strove to keep it balanced. The contributions made by Ricardo Uauy and Noel Solomons when preparing the scientific programme deserve special acknowledgment, but many others like Agneta Yngve, Javier Aranceta, and Barrie Margetts also contributed to a great extent.

The idea behind this congress stemmed from personal reflections regarding the need to reinforce the crucial area of public health, which has been neglected in most conferences concentrating on nutrition or public health, as well as the need to bring together professionals from the fields of science/academia and practice in a forum with an international perspective. These thoughts were discussed with certain colleagues who agreed about the need for such a conference. Similar feelings led to my founding of SENC (Sociedad Española de Nutrición Comunitaria/Spanish Society of Community Nutrition) in 1989, which, to my knowledge, was the first association created to serve this field. Although it is not easy to define public health nutrition (PHN), we should not complicate the task with debates that delay the recognition of this discipline in which academics and practitioners may converge to share and multiply their efforts to study and combat the nutrition-related disorders in both developing and developed regions. Epidemiologists, public health officers, health professionals, nutritionists, dietitians, economists, etc. who have accredited training and/or experience in PHN were the target audience of this congress. They were called on to participate and they responded. By May 2006, 1207 abstracts were received, and they were reviewed by a group of 10 individuals linked to both the scientific and the organizing committees. Over three entire summer nights, I made a particular effort to review each of the abstracts received.

Affiliation: L Serra-Majem is President of the I World Congress of Public Health Nutrition, University of Barcelona Science Park, Barcelona, and the Department of Clinical Sciences, University of Las Palmas de Gran Canaria, Las Palmas de Gran Canaria, Spain.

Correspondence: L Serra-Majem, Community Nutrition Research Centre, Parc Científic de Barcelona, Baldiri Reixac, 4, 08028 Barcelona, Spain. E-mail: Iserra@dcc.ulpgc.es, Phone: +34-93-403-4541.

Key words: congress, public health nutrition, World Public Health Nutrition Association 
The quality and importance of the communications confirmed my initial intuition about the need for the conference. The average of the 2 or 3 scores provided by the reviewers of each abstract was calculated and abstracts were selected, ranked, and classified as oral or poster sessions.

Organizing a first congress of any kind is not an easy task. Attendance of around 800 people was anticipated (typically, 400 participants attended the SENC congresses). Half of the estimated budget was expected to be covered by registrations and the other half by institutional and industry donations. After receiving 1207 abstracts, the forecasted participation was doubled as was the budget, since the number of proposed activities/ sessions increased from 25 to more than 50. Everyone wanted to participate in Barcelona! Most of the activities (32) were planned by the Executive and Scientific Committee and financed by the WCPHN congress itself, others (12) were planned by non-profit and independent organizations (the World Health Organization, universities, research networks, the European Commission, nongovernmental organizations, foundations, etc.) who, in these cases, covered the registration fees and local costs (lodging, per diems, etc.). A few sessions (6) were organized as symposiums by industry or by related institutions (less than 10\%). However, during the first months of 2006 only 100 abstracts had been received. This left us feeling a strange mixture of stress and confidence. National institutions either did not want or were unable to economically support this endeavor, but we did receive a significant contribution from the Catalan Ministry of Health in the form of 20 scholarships for registration fees. Through the support of other Foundations (the International Nutrition Foundation and the Nutrition Research Foundation), industry or industry-related institutional support, and SENC, the number of available grants was increased; this allowed for the participation of 82 researchers, the majority of whom were from developing countries. Selecting these 82 researchers from a total of 238 applications was not an easy task. Based on country eligibility and the abstract evaluation scores of the Evaluation Committee members, I had the task of ranking applications, taking into consideration the abstract scores, curriculum vitaes, and letters of support. This led to more sleepless nights and the unfortunate cancellations of some applicants who did not receive grants; as a result, their abstracts could not be considered. I personally feel that I should have worked harder to obtain more funds to cover these circumstances. Organizers, and particularly those private and public institutions that did not provide funds for grants, are responsible for the fact that these individuals were not able to participate. Issues of this nature need to be resolved in future WCPHNs.
The work of the Organizing Committee, composed of 15 public health nutritionists and myself, was crucial, as was the role of Reunions i Ciencia, the congress organizing headquarters. Each person in the committee was responsible for a key task and I would particularly like to acknowledge the contributions of Lourdes Ribas and Joy Ngo. We met more than 12 times over the span of more than 2 years in order to prepare for the Congress. Before the Congress, four workshops were organized in Spain: 1) "Nutritional Anemias" and 2) "Migration and Minorities: Overcoming Cultural Barriers", both in Barcelona; 3) "Epidemiological Methods in Estimating Food Consumption" in Reus, and 4) "Functional Foods" in Sitges. A total of 213 people attended these workshops, which took place simultaneously from 25 to 27 September. In addition, some satellite meetings were planned to take place prior to and during the Congress, which included meetings for the European Commission (EC) Cost 863 Euroberry Project, the New Nutrition Science Project, many research networks, and the Grupo Latinoamericano de Nutrición Comunitaria, among others.

I have always thought that most scientific congresses have little or no impact on the population, despite the media coverage in television, radio, and the newspapers, with international AIDS and tobacco conferences being exceptions. For this reason, on September 27 we organized the First Children's Congress on PHN, at which 327 schoolchildren aged 9-11 years from 18 different schools developed the Decalogue of Strategies for Preventing Childhood Obesity. To my knowledge, this is the first occasion on which children were systematically asked for their views on how to prevent obesity in themselves and their peers. We often plan preventive activities directed towards children without taking into account their beliefs, opinions, and desires. Related activities began in February 2006 in the 18 participating schools, and each of them presented their top 10 recommendations for obesity prevention that were then presented and ranked during the Children's Congress. Additionally, they participated in 10 different workshops prepared by various organizations. At the end of the Children's Congress, the following decalogue was approved:

\section{DECALOGUE OF STRATEGIES FOR PREVENTING CHILDHOOD OBESITY}

1) Physical activity is fun and really healthy for the body, but we are usually only physically active at school. We should also be active at home, especially on weekends: going bike riding together as a family, going hiking or to the gym, instead of being a couch potato.

2) Walk or bike to school.

3) Ask schools to provide parking space for bicycles near the school entrance. 
4) Walk up staircases whenever possible instead of using elevators.

5) Negotiate with parents for scheduling times to watch TV or play computer games.

6) During scheduled class breaks, drink water instead of sugared soft drinks and fruit drinks and juices.

7) Avoid candy and eating or snacking between meals.

8) Cook with parents on the weekends.

9) Celebrate birthdays and other parties with the healthiest foods.

10) Eat meals at the table only.

This is the essence of true PHN. The media had a great time covering the festive event, which included a closing ceremony complete with theater acts and music. Gemma Salvador and Assumpció Roset from the Organizing Committee were key players in orchestrating this event.

The I WCPHN began with speeches by Nevin Scrimshaw (via videotape due to a recent surgery), Igor de Garine, and José Maria Bengoa, who presented three complementary views of PHN, comprising the fields of basic research, anthropology, epidemiology, policy, and community action. In my opinion, one of the successes of this opening conference was to make evident the important role that Latin America has played in the field. Spanish-language contributions are often neglected in Anglo-Saxon points of view, and there are many examples of how key Spanish articles and texts are not considered in English-language publications. One such example is the recent and excellent book The Escape from Hunger and Premature Death, 1700-2100 by Robert William Fogel, which contains no citation of the extensive work of José Maria Bengoa. We are used to seeing systematic and personal reviews excluding Spanish citations, but what would the field of PHN be like without the existence of dozens and dozens of prominent and significant Latin American scientists contributing to it? One of the aims of this conference was to close that gap. The first talk after the emotive and unforgettable opening session was given by Michael Gibney of Trinity College, Dublin, Ireland, who brilliantly exposed the links between nutrition, genomics, and the metabolic syndrome from a public health perspective. The debate was moderated by Parvin Mirmiran from Shahid Beheshti University, Iran, and Chizuru Nishida from WHO Geneva.

The Catalan Ministry of Health and other national and local authorities officially opened the I WCPHN, which was organized under the auspices of the King and Queen of Spain. Barcelona is the capital of Catalonia, one of the autonomous regions that comprise the country of Spain. Catalonia has a specific national identity due to its history, culture, and language; it also has its own govern- ment and parliament that administer competencies in the areas of health, education, and culture, etc. Barcelona is a cosmopolitan city. It is international in scope and a defender of individual and collective rights as well as a proponent of the tolerance and dialogue between cultures. The city's appeal was most likely a contributing factor to the success of the I WCPHN Congress. The 1607 people who attended represented 79 countries (in decreasing order according to the number of attendees): Spain (more than 400); Brazil, the United States, Mexico, the United Kingdom (between 50 and 100); Germany, Argentina, Australia, Belgium, France, Iran, Italy, Portugal, Sweden, Switzerland (between 20 and 50); Austria, Canada, Chile, China, Finland, the Netherlands, Ireland, Lebanon, Norway, Poland, Venezuela (between 10 and 19); Andorra, Denmark, Greece, Guatemala, India, Israel, Japan, New Zealand, Peru, Republic of Korea, Romania, Russia, Serbia and Montenegro, South Africa, Thailand, Uruguay (between 5 and 9); and Saudi Arabia, Bahrain, Botswana, Cypress, Colombia, Costa Rica, Croatia, Cuba, Ecuador, Egypt, El Salvador, Slovenia, Ethiopia, Philippines, Ghana, Indonesia, Iceland, Kenya, Lesotho, Latvia, Libya, Lithuania, Luxembourg, Malaysia, Morocco, Nepal, Nigeria, Panama, Paraguay, Qatar, Czech Republic, Singapore, Sri Lanka, Taiwan, Tanzania, Turkey, Ukraine, Uganda (less than 5).

It is difficult to highlight only certain sessions and not cite them all, but I would particularly like to mention the following.

1) Sessions addressing standards/regulation: "Redefining hunger: need for better indicators", moderated by Reynaldo Martorell (Emory University); "Crossfire: Relationship between obesity and mortality risk. Do we know the cutoff points?", led by Ricardo Uauy (University of Chile); "Harmonizing growth and food and nutrition standards", moderated by Mercedes de Onis (WHO, Geneva); "Food and beverage marketing to children: selfregulation or legislation?”, moderated by Ingrid Keller (European Commission) and Francesco Branca (WHO, Copenhagen).

2) Sessions addressing updates and innovations: "Frontiers in nutrigenomics in cancer prevention", led by Ritva Butrum (World Cancer Research Fund/American Institute for Cancer Research) and John Milner (National Cancer Institute); "Vitamin $\mathrm{B}_{12}$, folic acid, and homocysteine", with Irwin Rosenberg (Tufts University) as moderator; "Developmental origins of health and disease: paradigm and paradoxes to challenge public health nutrition", moderated by Reynaldo Martorell (Emory University); "Weight-reducing diets. Are there any differences?", led by John Foreyt (Baylor College of Medicine); "Childhood obesity prevention: failures and successes", led by Philip James (London School of Hygiene and Tropical Medicine); "Community nutrition in Latin America", 
moderated by Cecilio Morón (ex- official FAO Food and Nutrition Programme); "Breaking the poverty/ malnutrition cycle in Africa and the Middle East", with Tola Atinmo (University of Ibadan) as moderator; and "Facing malnutrition and poverty: the CONIN experience" moderated by Luis Peña (University of Las Palmas de Gran Canaria). Apart from these sessions, others focused on new technologies in promoting nutrition and health, physical activity initiatives, antioxidant foods and health, micronutrients, the Mediterranean diet, breastfeeding, labelling, food service initiatives, and methodologies for evaluating nutrition status and designing and evaluating PHN policies.

3) Sessions addressing future directions in PHN: "What does it take to lead in PHN on a regional and global scale?", moderated by Barrie Margetts (University of Southampton); "Folic acid: to fortify or not to fortify?"; led by Mark Lawrence (Deakin University), "Nutrition action plan for the European region", moderated by Francesco Branca (WHO Copenhagen); and "Advancing international public-private partnerships for healthy nutrition and well-being" moderated by Eileen Kennedy (Tufts University), among others.

The Congress also made wellness a featured item through its Wellness Meeting Point to promote a variety of scheduled activities such as yoga, walking and biking trails, and even canoeing and night-time Nordic walking routes. To further promote physical activity, the congress materials included a tee-shirt and a pedometer to help attendees be active during their stay in Barcelona.

Apart from setting an example in promoting physical activity, the Congress featured the nutritious and flavorful qualities of Mediterranean cuisine in coffee breaks and lunches, focusing on whole grains, fruits, vegetables, nuts, and olive oil.

Congress exhibitors included food industry representatives, non-governmental organizations, PHN associations, private foundations, and scientific publishers. Some public health nutritionists are sceptical and opposed to private sector participation in these types of congresses. However, the reality is that a certain amount of industry support was required to fund this congress, as is the case with many others. I think it quite unfortunate that some specific industries did not support this event, and it's particularly worrisome that certain industries in the fast food and snacking areas never show any intention to participate. (Intention could be seen as a leverage point for negotiating changes in business practice, i.e., healthier products). It is my view that private-public partnerships are a feasible way to solve the major nutritional problems that challenge public health on a global scale, as experiences from other public health sectors, like vaccination, have shown. However, building these partnerships or alliances is not an easy task, since the interests of the involved parties may not always converge. For this reason, partnerships need to be completely transparent and regulated by ethical principles and a certain level of savoir faire - but this is another topic of discussion.

The Official Congress Dinner was held in the majestic Oval Hall of the Catalan National Museum, perched atop the Montjuic mountain overlooking Barcelona and surrounded by stately fountains accompanied by music and lights. Amid culinary creations provided by the oneMichelin-star-restaurant El Cingle, Congress participants enjoyed entertainment provided by traditional giant puppets, folk dances, and flamenco. Our head dietitian, Joy Ngo, was the surprise flamenco dancing feature.

The last session of the Congress included further outstanding presentations: one was by Barry Popkin (University of North Carolina at Chapel Hill), with comments by Philip James (London School of Hygiene and Tropical Medicine) and moderation by Ricardo Uauy (London School of Hygiene and Tropical Medicine), who was also the organizer; another was by Geoffrey Cannon (World Cancer Research Fund) and Claus Leitzmann (Justus Liebeig University), with Benjamín Caballero (Johns Hopkins University) as moderator and Irwin Rosenberg (Tufts University) providing insight and comments; the last was a session in which the topics of "Nutrition Transition" and the "New Nutrition Science" were protagonists for an interesting final debate between positions that are fated to converge. This was the icing on the cake.

The closing session was carried out by the Rector of the United Nations University, Professor Hans Van Ginkel, and myself.

One of the key outcomes of the Congress was my proposal to launch a new World Association of PHN to continue the momentum of the Barcelona Congress initiative. This proposal is geared towards improving nutrition-related health and well-being worldwide by acting to improve PHN locally, nationally, and internationally and by strengthening $\mathrm{PHN}$ practice and science.

The I WCPHN evoked such enthusiasm and impetus that its conclusion wrought an inevitable sense of loss. It is my hope that the next sessions of this Congress will maintain the same spirit felt by most of the attendees at the First World Congress of Public Health Nutrition.

\section{Acknowledgments}

I am forever indebted to the Organizing Committee of the I WCPHN: Lourdes Ribas Barba, Coordinator; Joy Ngo, Scientific Secretariat; Carmen Pérez Rodrigo, International Coordinator; and Eva Álvarez León, Immaculada Bautista, Jorge Doreste, Victoria Arija Val, Alicia García Álvarez, Blanca Gonzalvo Heras, Maribel Lopera Esteban, Gabriela Nicola Orejas, Rafel Peris Grao, Blanca Román Viñas, M. Assumpció Roset Elias, Gemma Salva- 
dor Castell, Margarita Serra Alias, Mercè Vidal Ibáñez. I would also like to express my gratitude to the Executive Committee: Javier Aranceta (Spain), Junshi Chen (China), Michael Gibney (Ireland), John Lupien (Italy), Barrie Margetts, (UK), Noel Solomons (Guatemala), Ricardo Uauy (Chile), Walter Willett (USA), Agneta Yngve (Sweden); the Scientific Committee: Ricardo Uauy (Chile) and Javier Aranceta (Spain); the Presidents; Tola Atinmo (Nigeria), Elliot Berry (Israel), Erick Boy (Canada), Ritva R. Butrum (USA), Benjamin Caballero (USA), Junshi Chen (China), David N. Cox (Australia), Mercedes de Onís (Switzerland), Hernán Delgado (Guatemala), Ibrahim Elmadfa (Austria), Michael Gibney (Ireland), Dun Gifford (USA), Serge Hercberg (France), Philip James (UK), Anna Jung (Belgium), Frans Kok (The Netherlands), Jeffrey Koplan (USA), Carlo La Vecchia (Italy), Barbara Livingstone (UK), John Lupien (Italy), Barrie Margetts (UK), Abel Mariné (Spain), Fernando
Monckeberg (Chile), Cecilio Morón (Argentina), Marion Nestle (USA), Delia Ana Nin (Argentina), Rosa Ortega (Spain), Andreu Palou (Spain), Chandrakant S. Pandav (India), F. Xavier Pi-Sunyer (USA), Pekka Puska (Finland), Juan Rivera (Mexico), Irwin Rosenberg (USA), Michael Sjöström (Sweden), Noel Solomons (Guatemala), Dimitrios Trichopoulos (USA), Antonia Trichopoulou (Greece), Helio Vannucchi (Brazil), Fernando Viteri (USA), Paul Walter (Switzerland), Walter Willett (USA), Yukio Yamori (Japan), Agneta Yngve (Sweden); Reunions i Ciencia (Rafel Peris, Cristina Blasco, Marta Manrique, Valentina Coppola, Laura Téllez); the Press Office (Icono Azul), the sponsors, authorities, and all the speakers and participants who collectively contributed to the success of the First World Congress of Public Health Nutrition.

Congress correspondence may be directed to: nutricom@pcb.ub.cat 